\title{
Internally Reporting Risk in Financial Services: An Empirical Analysis
}

\author{
Cormac Bryce $^{1} \cdot$ Thorsten Chmura $^{1} \cdot$ Rob Webb $^{1} \cdot$ Joel Stiebale $^{2} \cdot$ \\ Carly Cheevers ${ }^{3}$
}

Received: 20 September 2016/ Accepted: 2 April 2017/Published online: 26 April 2017

(c) The Author(s) 2017. This article is an open access publication

\begin{abstract}
The enduring failure of financial institutions to identify and deal with risk events continues to have serious repercussions, whether in the form of small but significant losses or major and potentially far-reaching scandals. Using a mixed-methods approach that combines an innovative version of the classic dictator game to inform prosocial tendencies with the survey-based Theory of Planned Behaviour, we examine the risk-escalation behaviour of individuals within a large financial institution. We discover evidence of purely selfish behaviour that explains the lack significance in pressure to adhere to the Subjective Norms of colleagues around intention to report risks. A finding that has potentially important implications for efforts to instil a high-error management climate and incentivise risk reporting within organisations where risk, if ignored or unchecked, could ultimately have consequences that extend far beyond the institutions themselves.
\end{abstract}

Keywords Risk escalation - Dictator game ·

Meta-analysis · Error management climate

\section{Introduction}

Trader 1: 'What's the call on the LIBOR'?

Trader 2: 'Where would you like it'?

Cormac Bryce

cormac.bryce@nottingham.ac.uk

1 Nottingham University Business School, University of Nottingham, Nottingham, UK

2 Hienirch-Heine University, Dusseldorf, Germany

3 Geary Institute, University College Dublin, Dublin, Ireland
Trader 3: 'Mixed feelings. But mostly I'd like it all lower so the world starts to make a little sense'.

Trader 4: 'The whole HF [hedge fund] world will be kissing you if LIBOR moves lower'.

Trader 2: 'Okay, I'll move the curve down one basis point-maybe more if I can'.

The above exchange, one of numerous intercepted interactions central to the high-profile case of traders manipulating the London Interbank Offered Rate, captures a fundamental truth about financial scandals: in many instances-arguably in all of them-the responsibility for reporting bad behaviour rests with the individual. The scandal, first revealed when Barclays Bank made multiple criminal settlements in 2012, illustrates the damaging repercussions of an organisation either failing to receive, or act upon, reliable information about happenings within its walls. So, too, do the high-profile controversies associated with the likes of Royal Bank of Scotland, UBS and the misselling of payment protection insurance (PPI). A controversy that engulfed almost the entire UK financial services sector and cost the industry billions. By 2014 Lloyds Banking Group alone had put aside $£ 9.8$ billion in compensation to victims of PPI mis-selling, whilst the cost to the industry in general had spiralled to more than $£ 20$ billion by early the same year. Interestingly, in line with this study, call centre staff were central to what took place.

The sheer preponderance of scandals, in tandem with the fallout from the crisis, has focused attention on how to increase the ethical climate of financial services organisations so as to encourage such internal risk reporting and reduce the likelihood of further 'risk events' (Martin and Cullen 2006; Gronewold et al. 2013). It is vital that management obtains reliable and accurate information regarding events, especially errors, within their own organisation 
regardless of whether such events are simple human error, or intentional actions that could have a harmful impact on the company. For example, $71 \%$ of the banking and finance industry employees questioned in a recent survey by KPMG "had "personally seen" or had "first-hand knowledge" of categories of misconduct within their organisations over the prior 12-month period'; moreover, more than half of these instances concerned 'misconduct that could cause a significant loss of public trust if discovered' (KPMG 2013, pp. 5-6). Such figures justify why the industry has also been pressurised from both governments and regulators to increase the robustness of their operations, increase reporting, reduce risk events and ultimately improve employee's ethical behaviour within it. It is therefore unsurprising that outwardly at least, these organisations have shown more interest in changing the way they operate, taking on-board regulation and complying with best practice.

Within financial services, most internal risk reporting falls under the area of 'operational risk management'. This is defined as 'the risk of loss resulting from inadequate or failed internal processes, people and systems or from external events' (BCBS 2006, p. 79). Much of the research, however, has not taken place within the financial services industry and has seen a variety of approaches and definitions within the ethical literature. For example, Ellis and Arieli (1999) apply the Theory of Reasoned Action model to investigate intentions to report infractions in a military setting; Kaplan and Schultz (2007) examine intentions to report questionable acts; Cassematis and Wortley (2013) explore whistleblowing and the non-reporting observer; Mayer et al. (2013) look into how employers can encourage employees to report unethical conduct internally; Gronewold et al. (2013) look at the reporting of self-made errors; and both Morrison (2011) and Wang and Hsieh (2013) examine the intentional withholding of information by employees.

In addition, a variety of theoretical approaches have been utilised with affective attachments (see Kenny 2014 for a rare banking example,) ethical climate theory and prosocial behaviour (see Dozier and Miceli 1985; Miceli et al. 2012; Victor and Cullen 1987; Van Dyck et al. 2005) all apparent in the literature. The theory of 'error reporting' and the ethical dilemmas it causes within organisations is well established in a number of industries including: Auditing (Gronewold et al. 2013); Aviation (Catino and Patriotta 2013) and Health care (Uribe et al. 2002). Such research has focussed upon particular types of error reporting, for example: slips and lapses (Leaver and Reader 2016a), self-made errors (Gronewold et al. 2013) and reporting colleagues (Miller and Thomas 2005). Interestingly, the most recent evidence surrounding error reporting has taken a human factors approach to investment banking error reporting (Leaver and Reader 2016a).
This paper takes its cue from error reporting theory and prosocial organisational behaviour/organisational citizenship (see Brief and Motowidlo 1986; Dozier and Miceli 1985; or more recently Miceli et al. 2012; Biron 2010) examining incentives to report important information to higher management. We relax the parameters of which type of error (risk event) is under investigation, as such we use the definition of internal operational risk reporting provided by Bryce et al. (2013, p. 300): 'the internal process by which real or potential risks are reported in a manner that complies with agreed institutional policy'. It is important to note that employees use this process in combination with the definition of what operational risk is (as detailed earlier) as a guide to what should be reported, and how, during their daily duties. In light of this process and the organisational norms that are attributed to it, an employee who fails to report would be deemed to be behaving in a way that it is morally unacceptable to the organisation (Treviño et al. 2006). Previous research by Gronewold et al. (2013) and Taylor and Curtis (2010) has paved the way for the placement of error reporting climate within the context of ethical behaviour due to this moral dilemma of whether to report or not.

The reporting of risk events is key in reducing the severity of losses through the implementation of controls and learning from incidents in line with Reason's (2000) idea of latent failures. It is also critical to how financial institutions model their risk losses to the regulator and maintain financial stability (Bryce et al. 2011). With these sometimes-competing objectives in mind, financial institutions have attempted to instil a 'high-error management' climate (Gronewold et al. 2013) in which the reporting of errors (in our case risk events) and the errors themselves are to be tolerated in an attempt to encourage ethical behaviour and ongoing error reporting (Van Dyck et al. 2005).

Our approach utilises an incentivised experiment to analyse an individual's level of altruism, prosocial behaviour and deception. In line with Bryce et al. (2013) we also employ the Theory of Planned Behaviour to interpret a survey designed to examine how an individual's relationship with their work environment influences their intention to report risk events. The setting for our analysis is a call centre of a major insurance company. Throughout the 1990s call centres were developed into strategically significant distribution vehicles for financial services (Malhotra and Mukherjee 2004). Given this distribution strategy their staff now often come into contact with real and/or potential risk events in their very earliest stages and are likely to be among the very first employees within a financial services hierarchy to face the choice of reporting a risk or not. For example, employees in this specific setting potentially encounter customers attempting to make 
fraudulent insurance claims or witness a colleague acting contrary to company policy, that is, moving off script whilst talking to customers on the phone, as was the case in PPI mis-selling.

Before explaining our methodology in detail, we offer a review of the literature on error and risk reporting, error management climate and individual behaviour in the workplace. We then extrapolate the literature to the realm of financial services institutions, examining the workerfirm relationship, incentives to act and the ethics of risk reporting.

\section{Literature Review}

Risk reporting in the workplace falls within the sphere of organisational behaviour, taking a multidisciplinary approach which draws upon applied psychology, sociology and applied economics (see Treviño et al. 2006; or Miceli et al. 2012 for an introduction). Past research, much of it building on the work of Kohlberg (1969) develops theories based on the notion that individuals bring into the workplace personal characteristics (e.g. moral awareness and moral judgment) that affect their behaviour. Victor and Cullen (1987) argue that these characteristics form the basis of an 'organisational ethical climate', providing a way in which to understand the reasoning and actions of employees. Especially relevant in the context of our study are facet-specific organizational climates (see Kuenzi and Schminke 2009 for a review) such as how the organisation itself deals with error reporting. These facet-specific climates are considered different, albeit related, to the overall work climate in that they are task (reporting a risk) or function specific (Schneider 1975).

For example, Martin and Cullen (2006) believe that all organisations have tangible and intangible norms and that identification with these norms leads to a shared climate (or climates) and this shapes the behaviour of individual employees (see Biron 2010; Peterson 2002; or Reichers and Schneider 1990). Arnaud and Schminke (2012) refer to a 'collective moral emotion' and a 'collective ethical efficacy', which Brown et al. (2005) argue are further influenced by the actions and relationships that managers have with their staff via their day-to-day conduct, personal actions and relationships-referred to in much of the ethics literature as situational factors (Trevino 1986; Church et al. 2005).

In addition, employees also bring their own individual morality and behaviour into the firm and actions are the result of these two factors: situational and individual, interacting with each other (see Trevino 1986). Situational factors affect an employee's individual sense of right and wrong when, in our setting, they encounter operational risk events, and this forms shared beliefs, norms and common practices regarding the management of error reporting in the organisation (Van Dyck et al. 2005). Thus, the interaction of the situational and the individual can lead an individual to make a decision to remain silent and ignore reporting important error events occurring around them (see Wang and Hsieh 2013) or actually undertaken by them (see Zhao and Olivera 2006).

Action or inaction is important within a work climate, where positive action, if viewed favourably by leaders, might be emulated by other members of a group (Haidt 2000, 2003; Romani and Grappi 2013) as previously discussed in relation to risk reporting by Bryce et al. (2013). In addition, Resick et al. (2013) find that 'deviant' acts are more likely to be reported if there is ethical leadership, whilst Landis et al. (2009) find a positive correlation between seeing other individuals acting virtuously and copying their behaviour-an occurrence known in the literature as 'moral elevation'. It is the intention of financial institutions to use this 'moral elevation' within a high-error management climate in order to improve operational risk reporting. Individual morality can be further disaggregated as being either: innate pure altruism or a variant, whereby individuals act in a 'prosocial' way with their actions being neither purely selfish nor purely altruistic.

Individuals who are prosocial can be more influenced by situational factors than those who are less prosocial, who instead have selfish tendencies with disregard for the environment around them (Grant and Berg 2011; Meglino and Korsgaard 2004). Moreover, individuals with high prosocial motivation take a more heuristic approach to their work and are more influenced by the group at the expense of their own interests (De Cremer and van Lange 2001). This is particularly pertinent in high-error management climates, where the ethical dilemma of both acting and being seen to act might help an individual's career prospects. Brief and Motowidlo (1986, p. 711) posit that prosocial behaviour has three facets and is:

- performed by a member of an organisation;

- directed towards an individual, group or organisation with whom he or she interacts whilst carrying out their organisational role;

- performed with the intention of promoting the welfare of the individual, group or organisation towards which it is directed.

Crucially, these arguments around prosocial behaviour are in contrast to one of the key assumptions of economic theory-that individuals invariably seek to maximise their own utility. As has been highlighted by the likes of Binmore (1994, 1998, 1999), Binmore and Shaked (2010), Hodgson (2012) and Thaler (1987), situational factors are accorded little (if any) value in the long-standing 
contention that individuals are both rational and selfish. As such, individuals will prize their own wealth or welfare above that of others if the rewards are sufficient and there is no punishment for acting otherwise. This theoretical understanding of how selfish individuals (call centre staff) can behave unethically in an attempt to maximise their wealth was borne out during the PPI mis-selling scandal due to the inappropriate incentivisation of staff.

In the financial services industry, and more specifically during the aftermath of the PPI scandal, it was common for management to impose sanctions for error creation with the intention of driving future compliant employee behaviour. Further, the potential costs (reputation, increased effort, loss of bonus) and negative emotions (fear, embarrassment, guilt) incurred in self-reporting an event should not be understated in this climate as highlighted by Zhao and Olivera (2006). In contrast the facet-specific 'high-error management climate' as posited by Van Dyck et al. (2005) is typified by open dialogue and communication with management around errors. This has the benefit of not only addressing errors in an attempt to correct them, but also in doing it in a timely manner, by placing less emphasis on punishment and more on learning from the incident. This 'time sensitivity' is particularly poignant in operational risk events as it is well documented in previous scandals that the longer a risk is latent (Reason 2000), the more severe the financial consequences for an institution it becomes, as was the case in the UBS example mentioned earlier. The IRM (2012) suggests that the more aligned individual responses are with an organisation's principles and values, the less likely it is that risk events will go unreported.

In contrast, the error reporting literature also argues that the move to punish, and fear thereof, can be considered as a characteristic of a facet-specific 'error-averse management climate' which may be counterproductive to the future reporting of operational risk events (Van Dyck et al. 2005; Van Dyck 2009; Gronewold et al. 2013; IRM 2012). In addition, the work of Morrison (2011) introduces the notion of the futility of expectation, arguing that an institution will suffer if an individual believes the reporting of events to be futile, particularly first reports, (see also Taylor and Curtis 2010; Van Scotter et al. 2005).

Encouragingly, the role of the individual within the organisational error management climate is also beginning to be recognised by the financial services industry. The nomenclature 'people risk' being used as a collective term to capture elements of both the 'organisational error management climate' and 'ethical climate' by both industry and regulators such as the Financial Conduct Authority (Bryce et al. 2013). However, the central issue has proved an especially difficult one to address effectively given the constant re-engineering of best practice and compliance requirements. At present, it appears that there remains a significant reliance on the individual to do the 'right thing', whether that be in how they conduct themselves or how they report the misconduct of others. It is also one of the aims of operational risk managers to avoid employee's remaining silent when they observe or commit types of behaviour not compliant with company policy or wider regulations, regardless of reason (Pinder and Harlos 2001; Van Dyne et al. 2003).

Despite this, it is possible to identify key drivers of the ethical and error management climate within this industry by drawing on the Financial Conduct Authority's (FCA) publication of 'Final Notices'. These notices are issued to institutions that have failed to adhere to the Principles of Business laid out by the FCA. They provide detailed independent documentation as to how these risk events have occurred and the reasons behind such failures. Given the sensitivity and financial severity of such failures, it is difficult to obtain such forensic information from the public domain. The use of these notices as a data source for forensic content analysis has recently been employed by Ring et al. (2014) when discussing the concept of risk culture and Ashton (2014) in relation to financial misselling.

We can usefully frame such an analysis by observing a small number of simple prerequisites. Each event must have:

- arisen from a 'common' people-risk issue

- resulted in a fine of more than $£ 1$ million

- taken place within a large institution.

Applying these criteria, we see that most cases revolve around a failure on the part of managers to put in place an adequate risk management system. This absence of controls appears to create problems around risk reporting, as even if the ethical and error management climate are strong, the infrastructure surrounding the organisation may make the reporting of risk events debilitating for an employee due to the sheer prevalence of real/potential risk events. As Table 1 illustrates, this is further exacerbated by many of the cases (61\% in total) citing insufficient or inappropriate training and skills as a contributory factor in the development and manifestation of risk within the organisation. This lack of training has been highlighted in previous research to not only negatively affect risk reporting (Bryce et al. 2016), but it has also been highlighted by Leaver and Reader (2016a) in the creation of risks at the operational level of an investment bank.

This rather worrying statistic around training only acts to reinforce the previous work of Bryce et al. 2013 and Power et al. (2013) as employees (no matter how intrinsically motivated to report) may simply not realise that what they have witnessed or done is worthy of escalating or worse, that it is their responsibility to do so (Leaver and 
Table 1 FSA Final Notices 2006-2011. Source: Authors own calculations derived from FSA Final Notices

\begin{tabular}{|c|c|c|c|c|c|c|c|}
\hline Year & 2006 & 2007 & 2008 & 2009 & 2010 & 2011 & Total \\
\hline No. of cases that met criteria & 10 & 8 & 5 & 8 & 10 & 10 & 51 \\
\hline No. of cases in retail sector & 7 & 8 & 4 & 1 & 4 & 8 & 32 \\
\hline $\begin{array}{l}\text { Value of } £ \text { fine } \\
\text { (\% of total for year-all fines) }\end{array}$ & $\begin{array}{l}4.97 \mathrm{~m} \\
(37 \%)\end{array}$ & $\begin{array}{l}4.45 \mathrm{~m} \\
(83 \%)\end{array}$ & $\begin{array}{l}15.94 \mathrm{~m} \\
(70 \%)\end{array}$ & $\begin{array}{l}28.32 \mathrm{~m} \\
(81 \%)\end{array}$ & $\begin{array}{l}69.32 \mathrm{~m} \\
(78 \%)\end{array}$ & $\begin{array}{l}52.16 \mathrm{~m} \\
(80 \%)\end{array}$ & $\begin{array}{l}206.84 \mathrm{~m} \\
(89 \%)\end{array}$ \\
\hline Breach of principle 2 & 7 & 2 & 1 & 3 & 2 & 0 & 15 \\
\hline Specific mention of breach of principle 3 & 10 & 8 & 4 & 8 & 7 & 5 & 42 \\
\hline Specific mention of breach of principle 9 & 0 & 1 & 1 & 0 & 0 & 4 & 6 \\
\hline Specific mention of breach of principle 6 and 7 & 5 & 4 & 3 & 1 & 1 & 0 & 14 \\
\hline Specific mention of lack of training as an issue & 6 & 6 & 4 & 7 & 2 & 9 & 34 \\
\hline
\end{tabular}

Reader 2016a). This is pertinent to the operational risk discipline as unlike credit and market risk, every employee (regardless of role) has the potential to be exposed, or expose the organisation, to operational risk within their work environment. This has led the financial institution under investigation to employ a very basic risk readiness mantra of 'see something, say something' through continual professional development and introductory courses in operational risk for all employees during induction. However, given the broad scope of professions within a financial institution it must be noted that the influence of professional identity (Taylor and Curtis 2010) has yet to be considered in operational risk reporting and may actually be a weakness in the reporting process currently, as so many backgrounds and professions are responsible for reporting. This concept of professional identity is particularly important for the subject group under investigation as their profession (call-handler) has little by way of professional memberships or external accreditation. Although Table 1 provides a snapshot of the importance of the individual in dealing with risk events, the significance of the relationships and influences between financial services employees and their institutions has been the subject of little research (see McCabe 2009 Kenny 2014; Leaver and Reader 2016a, b).

In the context of our paper, we are interested in the organisational error management climate, how organisations react to operational risk events when reported, and how these reactions affect employee's intention to act morally and report future risk events as they arise. The financial services industry is still coming to terms with the day-to-day relevance of operational risk, especially with regards internal risk reporting. Operational risk remains commonly viewed as something to be observed-chiefly in the interests of complying with regulations (see Bryce et al. 2011; or Palermo et al. 2016). A KPMG survey of 500 senior managers involved in risk management within financial institutions reported that only $42 \%$ planned to make fundamental changes to their processes, 'suggesting a degree of complacency' (KPMG 2009, p. 5) in processes of their organisational error management climate.

All of which provides the basis for our method which is not entirely without precedent as work by Ellis and Arieli (1999) examined intentions to report infractions utilising the Theory of Reasoned Action. Our approach will enable us to (1) examine the level of prosocial behaviour involved in the decision to report risk events within a financial institution, (2) identify links with individual's perceptions of the institution, (3) determine the prevalence of a higherror management climate or error-averse climate and (4) observe employee deception towards colleagues. For example, if we find high levels of prosocial behaviour in our experiment, we envisage this would lead to more positive results regarding intention to report, an indicator of a high-error management climate.

Our use of an adapted form of the dictator game in combination with the Theory of Planned Behaviour (Ajzen 1988, 1991) extends the work of Bryce et al. (2013). The rationale for using intention to report operational risk is embedded in the 'see something, say something' mantra of risk awareness and anticipation outlined by the institution under investigation (Rybowiak et al. 1999; Zhao and Olivera 2006). Further, given the limited time afforded to the research team to enter the organisation and investigate their employees it was not feasible to monitor risk reporting behaviour directly given the timeframes and access required to conduct an ontological study. A more detailed psychological rationale for the use of intention as a predictor of behaviour is detailed below.

\section{Methodology and Hypothesis Development}

Our analysis of internal risk reporting within a financial institution was carried out at a site responsible for more than $£ 45$ million in turnover for the period 2012-2013. Our mixed-methods approach consisted of two modules; Module 1-a derivation of the classic 'Dictator Game' 
economic experiment and Module 2-the survey-based 'Theory of Planned Behaviour'. This integration of economic experiments and survey-based elicitation techniques to gain additional insights into elements of ethical climate, error-climate and prosocial behaviour in our study has seen a steady rise in popularity within the literature. Recent examples of this approach include the study of risk preferences (Fehr et al. 2003; Dohmen et al. 2011), organisational whistle-blowing (Burks and Krupka 2012), trust (Naef and Schupp 2009) and personality (Ben-Ner et al. 2004). In this current study, setting the inference of behaviour via surveys and observation of behaviour via experiments provides a complementary approach to the understanding of internal risk reporting within a large financial services organisation.

\section{Module 1: The Adapted Dictator Game}

The dictator game is a well-known behavioural economics experiment that tests altruistic and prosocial behaviour (Kahneman et al. 1986; Forsythe et al. 1994; Bardsley 2008; Eckel and Grossmann 1996; Dana et al. 2006). In the classic dictator game, a first player the 'dictator' is required to determine how to split an allocation of money with a second player the 'recipient'. The recipient simply receives the amount the dictator chooses not to claim; the recipient's role is therefore completely passive. The game is most commonly acted out as a one-off interaction, with no scope for role reversal or repeated plays based on gained information. If individuals were wholly rational and motivated purely by their own welfare, as suggested by classical economic theory, 'dictators' would keep the entire allocation for themselves and send nothing to recipients.

For our version of the dictator game we prepared 90 envelopes containing eight $£ 1$ coins (£8) and 10 envelopes containing four $£ 1$ coins and four chocolate coins $(£ 4+4)$. All of the envelopes were placed in a box, and each subject was asked to remove one at random. Subjects were advised of the two types of envelopes but not of the 90/10 split. In contrast to Ben-Ner et al. (2004), we did not allow reciprocity and played the game without role reversal.

Each subject was asked to open their chosen envelope, examine the contents and decide how much to keep and how much to send to a colleague in another call centre. The allocation to be sent to the 'recipient' was then resealed in the envelope and placed in a second box. We placed the two boxes in a separate room to ensure subjects behaviour was private and anonymous which is common practice for experiments dealing with unethical behaviour (Fischbacher and Föllmi-Heusi 2013). The sent funds would be used to buy coffee (in line with Khadjavi and Lange 2013) by the 'recipient' in a sister call centre. To this extent, our game essentially mirrored the original dictator game.
However, we introduced the possibility of deception by placing next to the second box a jar containing 500 chocolate coins. Each 'dictator' was free to put chocolate coins into their envelope (in the case of a $(£ 4+4)$ envelope being selected, of course, a 'dictator' could also remove chocolate coins from their envelope). This allowed them to pretend to have drawn a $(£ 4+4)$ envelope by giving the 'receiver' an impression of having behaved fairly and shared equally, when in reality they had drawn a cash-only (£8) envelope and kept three quarters of the money. A similar experimental set-up (albeit using the ultimatum game) was first introduced by Guth et al. (1996) in which 'dictators', who in the context of our study received the larger envelope $(£ 8)$, sent the fair offer of the $(£ 4+4)$ envelope, to maximise their profits and to disguise the true size of their initial envelope. This modification enabled us not only to observe incidents of unethical behaviour in the form of deception but to measure selfishness, prosocial and altruistic behaviour (Hoffman et al. 1994; Engel 2011). Further, the use of chocolate coins by subjects to replace real money and deceive their counterparts will also provide an experimental indication of the ethical climate and prevalence towards 'covering up' which typifies an error-averse organisation.

Although in our experiment all decisions were made in isolation in a separate room, with no means of tracing them back to subjects, they were told there was a $2 \%$ chance that the original value of an envelope would be revealed. This was not an arbitrary figure: it was provided by the institution as the percentage of financial products mis-sold each month and was therefore representative of identifiable risk events that would require reporting. Our intention here was to suggest that deception might be detected, providing a real and obvious threat. This 'reveal' mimics the real-life work environment within the call centre as employees in contact with regulated financial products have their calls recorded with monthly reviews of their adherence to institutional policies.

What should we expect to find? The unflinching rationality championed by textbook economic theory would see dictators keep everything and give nothing (Binmore 1994), but the results ought to be somewhat less straightforward if we take into consideration the environment in which these subjects will be situated. As Engel stated in his meta-study $(n=616)$ of the dictator game (2011, p. 584):

While normally a sizeable fraction of participants does indeed give nothing, as predicted by the payoff maximisation hypothesis, only very rarely has this been the majority choice. It is by now undisputed that human populations are systematically more benevolent than homo economicus. 
In other words, purely selfish behaviour tends to be discovered but is by no means the norm. Engel reports that 'dictators' are more likely to give a little than a lot-on average sending 'recipients' $28.35 \%$ of the available total-but in only six of 616 treatments surveyed do they give an average of zero. Importantly, though, most experiments based on the dictator game have not been carried out in a corporate setting. Comparing our results with Engel's meta-study should therefore shed light on the levels of individual morality and the influence of situational pressures to act ethically within the workplace.

\section{Module 2: The Intention to Report Operational Risk Events Survey}

All 62 of the employees who took part in the adapted dictator game also took part in our survey, which was again carried out in isolation and away from fellow employees and members of the research team. The sample was almost equally split between male and female staff and dominated by customer-facing employees and risk managers; over half of the subjects had been at the institution for more than three years. Descriptive information on the respondents is provided in Table 2.

Structuring questions pseudo-randomly to minimise respondent bias, we used seven-point Likert scales that invited responses ranging from 'strongly agree' $(+3)$ to 'strongly disagree' (-3). Please see 'Appendix 3' for items used in this survey. Analysis was carried out using PASW version 18, with regression analysis used to assess the relevance of the Theory of Planned Behaviour (Ajzen 1988, 1991). The Theory of Planned Behaviour (TPB) disaggregates an individual's behavioural Intentions (INT) into three antecedents:

- Attitude (ATT) — the individual's attitude towards the behaviour

- Subjective Norm ( $\mathrm{SN}$ - - a measure of the perceived degree of pressure from surrounding sources

- Perceived Behavioural Control (PBC) - the perception of control over the final outcome of the behaviour.

These three variables combine to influence a subject's intention (Dennison and Shepherd 1995) to report risk events. The use of intention as a predictor of behaviour is grounded in the psychological literature and conceptual frameworks that develop it such as the Theory of Reasoned Action, Theory of Planned Behaviour and Technology Acceptance Model. Intention is considered a strong indicator of actual behaviour in various settings including job seeking behaviour, smoking cessation and technology uptake (Ajzen 1988, 1991, Bryce et al. 2013; Hsu and Chiu 2004; Lin 2010). In this current setting, the intention to report is central to the error management climate within the
Table 2 Descriptive statistics of respondents

\begin{tabular}{lcc}
\hline Characteristic & Frequency & $\%$ \\
\hline Gender & 34 & \\
Male & 28 & 54.8 \\
Female & & 45.2 \\
Role within the institution & 38 & \\
Customer facing & 8 & 61.3 \\
Manager/team leader & 16 & 12.9 \\
Risk manager & & 25.8 \\
Length of time at the institution & 4 & 6.5 \\
$0<6$ months & 9 & 14.5 \\
6 months $\geq 1$ year & 17 & 27.4 \\
1 Year $>3$ years & 11 & 17.7 \\
3 years $\geq 5$ years & 21 & 33.9 \\
5 years + & & \\
Length of time in current role & 8 & 12.9 \\
$0<6$ months & 10 & 16.1 \\
6 months $\geq 1$ year & 24 & 38.7 \\
1 year $>3$ years & 7 & 11.3 \\
3 years $\geq 5$ years & 13 & 21.0 \\
5 years + & & \\
\hline
\end{tabular}

organisation as Van Dyck et al. (2005) state that communication about errors constitutes the most important error management practice. The three antecedents correspond closely with the idea that actions and responses are the result of the interaction between the individual and the situational (Trevino 1986) and that behaviour within organisations is at least in some way influenced by an amalgamation of individual morality, collective moral emotion and work climate (Kish-Gephart et al. 2010).

ATT acts to determine an individual's beliefs around the behaviour in question. For our purposes, it indicates whether some individual thinks reporting a risk event is worthwhile. We expect that ATT will be influenced by a combination of individual prosocial behaviour, ethical climate, error-climate and perceived significance of the event itself. In essence, the individual needs to be convinced that an event is important and requires reporting. $\mathrm{SN}$ relates to the social pressure to report a risk event. This pressure might come from the members of an individual's team, from line managers or from regulators. It is directly linked to the idea of embedded notions of behaviour within a financial services organisation, as discussed in Ring et al. (2014). As explained earlier, groups within organisations identify with norms, giving rise to a shared climate (Reichers and Schneider 1990) and producing an environment that influences the conduct of individual staff members.

$\mathrm{SN}$ has been found to be significant in intention to report (more so than ATT) in related work, albeit in a different institutional setting (the Israeli Defence Forces, see Ellis 
and Arieli 1999). In contrast, Bryce et al. (2013) report SN to be insignificant, this may be due to a lack of awareness or the ethical climate of those working in financial institutions. Work by Moosa (2007), Power (2007) and Hain (2009) argues that reporting misconduct in financial institutions might be constrained by various factors, including a disruptive environment (e.g. a blame culture), a financial penalty on the institution, or fear of discrimination by colleagues. All of which can be attributed to characteristics of an averse-error management climate (Van Dyck et al. 2005). In contrast, recent regulatory requirements imply that line managers should react positively to the escalation of risk events in line with the characteristics of a high-error management climate.

PBC represents an individual's perceptions of seeing actions through to a successful conclusion which may not necessarily be as easy as first thought given the lack of action taken by early whistle-blowers as indicated by Van Scotter et al. (2005). This variable is again linked to interactions within the work climate in which employees find themselves. Venkatesh and Brown (2001) and Pavlou and Fygenson (2006) indicate that 'ease of use affects the control an employee believes he or she has over reporting an event, whilst Arnaud and Schminke (2012, p. 1768) note:

Members of a work unit may know the right thing to do, but if they feel confident in their collective ability to bring about the desired outcome they are more likely to follow through with doing it.

Arnaud and Schminke (2012), like Bandura (1986) before them, also highlight the significance of 'self-efficacy', which for our purposes relates to the competence of staff to report risk events. Other studies, among them Eden and Aviram (1993), Saks and Ashforth (2000), Ma and Liu (2005) and Chan and $\mathrm{Lu}$ (2004) endorse this theme. Accordingly, we consider 'self-efficacy' and 'ease of use' within the $\mathrm{PBC}$ construct whilst keeping in mind the outcomes of our initial investigation of Final Notices, which highlighted the ineffectiveness of the risk management system, which in part entails the 'ease of use' of the risk reporting process.

Given the above, our first three hypotheses apply those of Ajzen (1991) via the prism of the specific setting of our study. They are as follows:

H1 ATT positively affects intention to escalate operational risk events

H2 SN positively affects intention to escalate operational risk events

H3 PBC positively affects intention to escalate operational risk events
In an effort to help explain the variance in behavioural intention, we further adapt the TPB to include additional variables beyond those originally proposed by Ajzen (1988). The openness of the TPB to the inclusion of further explanatory variables is considered key to this current study. The role of 'uncertainty', as considered by Bryce et al. (2016) is one of these additional antecedents. It has been shown that education and training can alleviate uncertainty, with employees gaining more understanding of their roles and responsibilities and developing their ability to identify potential risk events (Power 2005; Mikes and Kaplan 2013; IRM 2012; Leaver and Reader 2016a). However, our initial investigation of the Final Notices in Sect. 2.1 highlighted that the majority of cases included insufficient or inappropriate training and skills of employees. This makes it difficult for them to be certain that a real or potential risk event had occurred and what to do should they realise, relating back to the concept of risk awareness and readiness that the organisation under investigation was striving for. This leads us to the following hypothesis:

H4 Uncertainty negatively affects intention to escalate operational risk events

We also examine the intrinsic motivation of employees to report risks and the importance of their decision to engage or disengage with the work environment's protocols and procedures, as per the norms referred to by Martin and Cullen (2006) and more specifically Van Dyck et al. (2005). It may be, for example, that members of staff who fully reflect on the reporting process and value their own track records in risk management have a stronger intention towards the reporting of risk events, a view closely linked to the characteristics previously discussed of a high-error management climate. This is closely linked with and adds further support to $\mathrm{PBC}$, in that an employee who understands structures and protocols will have more knowledge about the level (or probability) of his or her control over the ultimate outcome. This brings us to our final hypothesis:

H5 An employee's risk integrity positively affects intention to escalate operational risk events

\section{Results and Discussion}

\section{Module 1 Results: The Adapted Dictator Game}

A total of 62 subjects played our adapted version of the dictator game. Of these, 55 'dictators' picked a cash-only envelope (£8) and seven picked a cash/chocolate envelope $(£ 4+4)$. Figure 1 shows the variance in decision-making of gift amounts sent to the 'recipient' for those 'dictators' 


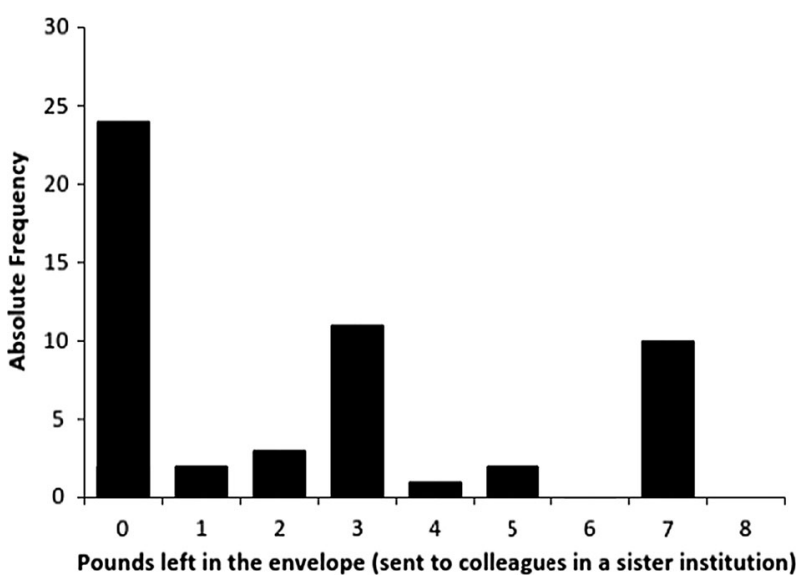

Fig. 1 Distribution of coins left in envelopes (subjects who initially received eight $£ 1$ coins)

who picked the (£8) cash-only envelopes. Twenty-four of the fifty-five 'dictators' in this treatment (44\%) kept all the money for themselves. The figure is higher than the average reported by the meta-study conducted by Engel (2011), who found around $36 \%$ of 'dictators' give nothing, and more closely corresponds with the theoretical literature of pay-off rationality. It also suggests the $2 \%$ probability of the original sum being revealed to the 'recipient' had minimal influence on behaviour for these subjects.

As well as fitting the notion of the economic agent as maximiser (Binmore 1994, 1998, 1999; Binmore and Shaked 2010; Hodgson 2012; Thaler 1987), this result helps interpret the two dimensions of the dictator game explored in the literature-one asserting that behaviour is universal, the other examining the effect of situational circumstances (Trevino 1986). Our finding shows that employees in financial institutions are more likely than on average to take everything, thus exhibiting more purely selfish behaviour than the general population.

We do, though, also find some evidence of altruistic/ prosocial behaviour. Eleven of the fifty-five subjects (22\%) who picked a (£8) cash-only envelope favoured an equal split, keeping $£ 4$ for themselves and gifting the remaining $£ 4$. This is in line with purely altruistic and prosocial behaviour, with the latter an adapted form of altruism in which positive social behaviour does not solely benefit others but also rewards the individual (Falk et al. 2003; Church et al. 2005).

This, too, is an important finding, as it has been argued that prosocial behaviour must be present in some form for an individual to report a risk event and to create a higherror management climate (Dozier and Miceli 1985, Van Dyck et al. 2005). Interestingly, Engel (2011) finds that on average around $17 \%$ choose an equal split-somewhat less than we find in our environmental setting. It is possible that some kind of situational pressure may be at play, which further highlights the value of conducting our experiments in situ. In addition to this, given the experiment was run in the work environment, and the fact that 'receiver' is a colleague in a sister call centre, it may engender beliefs of team membership and citizenship. Previous research suggests higher cooperation rates when we look at other studies conducted in team and group environments, for example Goette et al. (2006) show a higher cooperation rate when subjects are paired with a member of their own group in the prisoners' dilemma. This is also supported by Chmura et al. (2016) in which group members have more trust and higher beliefs of reciprocity when paired with a subject from the same community. Our findings also support the work of Landis et al. (2009) who introduced the notion of moral elevation, that is, a positive correlation between seeing other individuals acting virtuously and copying their behaviour.

Evidence of altruism in its purest sense (Leeds 1963), whereby the 'dictator' receives no gain whatsoever, is also witnessed, with 10 of the 55 subjects $(18 \%)$ who picked the (£8) cash-only envelope keeping nothing. This result is much higher than the average for studies of this type, the Engel (2011) meta-study of 616 treatments only finds an average of just $5 \%$, taken with the levels of prosocial behaviour already reported, this result further adds to the notion that individuals may be reacting to situational pressures in the workplace. It is worth noting that the literature indicates such altruism is more evident if money is to be sent to colleagues or charitable institutions. As such, individual and situational factors may be combining (Wang and Hsieh 2013), this was also found in the work of Chmura et al. (2010) where a higher altruism rate is also observed for prisoners from the same correctional facility. In the context of our study, the work environment stimulates a 'team spirit' that leads employees to feel closer to each other compared to other randomly matched subjects in other studies. Overall, employees who picked the (£8) cash-only envelopes sent $35 \%$ of the total available money to receivers-again a figure higher than reported in Engel's (2011) meta-study (28\%).

In summary, as Fig. 1 illustrates, our financial institution produces results that are three-peaked for those who randomly chose the cash-only (£8) envelope. Although individual pay-off maximisation dominates, employees who choose to give some portion of the money exhibit more prosocial behaviour than on average for this game. This illustrates the influence of situational factors combining with individual traits. Those $44 \%$ who kept all the money for themselves demonstrate lower prosocial motivation and greater rationality in the textbook economics sense and may be ignoring influences such as reporting policies, work climate and collective moral emotion (Meglino and Korsgaard 2006; Simon 1993) in their duties. 
Table 3 Distribution of coins left in envelopes

Coins of type remaining in the envelope

0

$1 \quad 2$

$2 \quad 3$

4

5

Employees selecting envelope with $4 £ 1$ coins and $4 £ 1$ choc coins $£ 1$ chocolate coins found in the envelope

$£ 1$ coins found in the envelope

Employees selecting envelope with $8 £ 1$ coins

$£ 1$ chocolate coins found in the envelope (no $£ 1$ coins)

$£ 1$ coins found in the envelope (no chocolate coins)

\begin{tabular}{lllllllll}
1 & - & - & - & 5 & - & - & 1 & - \\
3 & 1 & - & 1 & 2 & - & - & - & - \\
16 & 1 & 5 & 1 & 15 & 0 & 1 & 3 & 13 \\
24 & 2 & 2 & 3 & 11 & 1 & 2 & 0 & 10 \\
\hline
\end{tabular}

As shown in Table 3 and Fig. 2, analysis of how those subjects who picked cash-only envelopes (£8) used the chocolate coins also reveals a three-peaked distribution. Nearly $30 \%$ chose not to put any chocolate coins back in the envelope, thus showing no intention to deceive their recipient colleagues; almost $24 \%$ filled the envelope with eight chocolate coins, indicating not only pay-off maximisation but little prosocial behaviour and no apparent willingness to conceal their actions; and 27\% placed either four or six chocolate coins in the envelope. This indicates that individual factors are at play, and that employees will bring their own moral and ethical behaviour into the institution. As all employees in the subject pool are working under the same facet-specific ethical and error-climate-our results provide evidence of a diverse level of individual morality and ethical behaviour within the workforce.

This is further evidenced by the last of these peaks, which suggests a desire to deceive the 'recipient' by appearing to act in their interest. Placing four chocolate coins in the envelope indicates at least a measure of deception, as it might lead the 'receiver' to believe a cash/chocolate envelope was originally picked. Placing six chocolate coins in the envelope-surprisingly, a ploy chosen by only one subject-indicates total deception, the hope being that the receiver concludes that a cash/chocolate envelope was

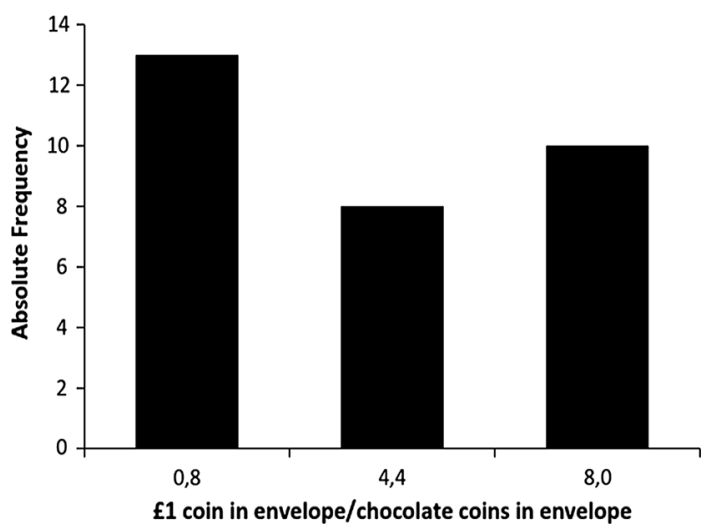

Fig. 2 Deceptive use of chocolate coins? (All other possible combinations had a frequency $\leq 3$ ) (subjects who initially received eight $£ 1$ coins) originally picked and the money was split evenly. Overall, almost half of the subjects who picked cash-only envelopes $(46 \%)$ removed all or some of the money and used chocolate coins to restore the eight-coin total.

The use of chocolate coins to deceive is most apparent among those subjects who picked cash/chocolate envelopes. Although the small number of respondents who selected these envelopes does not necessarily lend itself to establishing reliable trends, it is possible to discern purely selfish behaviour and attempted deception, since three subjects (43\%) took all the money and left the four chocolate coins; as Table 4 shows, no two of the remaining four subjects took the same course as each other.

Taking these results as a whole, the key point is that all three types of behaviour-selfish, altruistic and prosocialare clearly in evidence and higher than the average reported by Engel's (2011) meta-study of the dictator game. The question is whether this is a consequence of the influence exerted by our chosen setting of a financial institution. It is apparent that a large proportion of the subjects have no issue with covering up, and deceiving colleagues with chocolate coins, even with the existence of a real threat. This may be indicative of their lack of intention to report errors, particularly those errors that may involve financial loss for themselves in reporting. To examine these findings in more detail whilst applying the lens of error management climate we turn to the Theory of Planned Behaviour.

\section{Module 2 Results: The Intention to Report Operational Risks Survey}

Previous research suggests that the findings from our adapted dictator game could inform each of our TPB variables-Attitude (ATT), Subjective Norm (SN) and Perceived Behavioural Control (PBC)—especially given the contention that behaviour within organisations is at least in some way influenced by a combination of individual morality, collective moral emotion and work climate (Kish-Gephart et al. 2010). Since TPB is particularly dependent on the interaction of individual and situational 
Table 4 Subject randomly selecting 4/4 split envelopes

\begin{tabular}{ll}
\hline 1 coins remaining/chocolate coins remaining & Frequency \\
\hline $0 / 4$ & 3 \\
$1 / 7$ & 1 \\
$3 / 4$ & 1 \\
$4 / 0$ & 1 \\
$4 / 4$ & 1 \\
\hline
\end{tabular}

factors within an organisation, our finding that purely selfish behaviour dominates both purely altruistic and prosocial behaviour could be significant.

Table 5 presents the results of our Pearson correlations, including means, standard deviations and Cronbach alpha, for all constructs within the study. The original aspects of TPB are all significantly and positively associated with each other, with all other constructs also significantly associated with Intention (INT). Given the importance of, and requirement for, communication in a high-error management climate in which latent errors are prevalent, it is reassuring to see a positive INT scale average of 5.828, stronger than previous studies in a similar environment (Bryce et al. 2013). Interestingly, the strongest correlation is PBC with INT ( $r=0.627)$, which, whilst not conclusive, provides some evidence of the assertion of Arnaud and Schminke (2012) that confidence of achieving a desired outcome affects behaviour. In line with the work of Bryce et al. (2016), uncertainty is negatively associated with both INT and ATT, thus confirming the robustness of our variable selections. Adequate internal reliability is present, as indicated by the Cronbach alpha values in the bottom row of the table (Nunnally and Bernstein 1994; Cronbach 1970).

A four-stage hierarchical regression model was used to analyse the TPB and test for any significant causal effects of our constructs. Table 6 shows the results. Model 1, which includes the three basic variables making up TPB, is significant $(F(3.58)=18.482, p<0.001)$, with the adjusted $r^{2}$ explaining $46 \%$ of the variance in INT. The results show that ATT towards escalating a risk event and PBC over the final outcome of such a course of action are both positive and significant, indicating the presence of the characteristics of a high-error management work climate in our financial institution such as the positive link between attitudes (behaviours) towards, and commitment. To organisational goals (reporting) thus allowing us to accept $\mathrm{H} 1$ and H3. This alignment of organisational goals and reporting (particularly detection) by employees was highlighted by Roberts and Bea (2001) during their seminal study of high reliability organisations. These findings highlight two important points. The first is that an individual who chooses to report a risk event must believe that doing so is worthwhile and relate to a larger organisation strategy. The second is that an individual who chooses to report a risk event must believe that doing so will be both productive and straightforward.

Broadly in line with the work of the IRM (2012), these are key considerations in attempts to devise and implement policies that encourage risk reporting within organisations. Further, the importance of learning from incidents to the organisation as explained in the induction courses for all new members of staff (both in terms of why employees should, and the outcomes from the reporting behaviour) serves to satisfy both these points. This highlights the importance of an effective risk management system, in which the reporting process resides, as detailed in our analysis of the Final Notices and typifies the characteristics of a high-error management climate within the institution under investigation.

Further, in line with Bryce et al. (2013) but in contrast to the work of Ellis and Arieli (1999) and (with a little knowing extrapolation) to the work of Miceli et al. (2012) SN is found to be insignificant. The models show that the influence of others-for example, the 'team' is inconsequential, we therefore reject $\mathrm{H} 2$. This may appear a surprising finding, but it is one on which the results of our adapted dictator game shed some light. As reported above, the literature suggests prosocial individuals are more influenced by situational factors than those who exhibit selfishness, who instead tend to disregard their environment and those around them and value their own opinions above those of others (Grant and Berg 2011; Meglino and Korsgaard 2004). Our survey poses
Table 5 Pearson correlations between survey items

\begin{tabular}{lcccccc}
\hline & 1 & 2 & 3 & 4 & 5 & 6 \\
\hline 1. Intention & & & & & & \\
2. Attitude & $0.470^{* *}$ & & & & & \\
3. Subjective Norm & $0.483^{* *}$ & $0.405^{* *}$ & & & & \\
4. Perceived Behavioural Control & $0.627^{* *}$ & $0.326^{* *}$ & $0.481^{* *}$ & & & \\
5. Uncertainty & $-0.608^{* *}$ & $-0.350^{* *}$ & $-0.337^{* *}$ & $-0.529^{* *}$ & & \\
6. Risk integrity & $0.448^{* *}$ & 0.156 & 0.120 & $0.273^{*}$ & $0.434^{* *}$ & \\
Mean & 5.828 & 6.182 & 5.431 & 5.362 & 2.860 & 4.328 \\
SD & 0.806 & 0.634 & 0.911 & 0.970 & 1.095 & 0.916 \\
Cronbach alpha & 0.81 & 0.66 & 0.83 & 0.78 & 0.78 & 0.68 \\
\hline
\end{tabular}

** Correlation significant $p<0.01, *$ Correlation significant $p<0.05$ 
Table 6 Results of multivariate regression analysis

\begin{tabular}{llll}
\hline Model & $1 \beta$ & $2 \beta$ & $3 \beta$ \\
\hline Attitude & $0.253^{*}$ & $0.229^{*}$ & $0.192^{*}$ \\
Subjective Norm & 0.154 & 0.167 & 0.152 \\
Perceived Behavioural Control & $0.470^{* *}$ & $0.395^{* *}$ & $0.310^{* *}$ \\
Risk integrity & & $0.285^{* *}$ & $0.214^{*}$ \\
Uncertainty & & & $-0.233^{*}$ \\
$R^{2}$ & 0.489 & 0.563 & 0.596 \\
Adj $R^{2}$ & $0.462^{* * *}$ & $0.533^{* * *}$ & $0.560^{* * *}$ \\
Sig F change & 0.000 & 0.003 & 0.038 \\
\hline
\end{tabular}

Examination of tolerance, VIF and condition indices indicated no violations of multicollinearity or collinearity for all elements in the table

$* * * p<0.0001 ; * * p<0.001 ; * p<0.05$

specific questions regarding others' views of reporting risk events, and these may be dismissed by the purely selfish who make-up nearly half of our subjects. This again points towards the intention to report a risk event being reliant on the attitude of the individual towards the event itself and the ability of the individual to perceive control over the path to a positive outcome. Further, the lack of a professional body to provide an identity, and guidance on best practice for the call centre staff over and above what the organisation itself is instilling may hinder the effects of $\mathrm{SN}$ on intention to report risk events. The work of Taylor and Curtis (2010) and Kaplan and Whitecotton (2001) has highlighted the importance professional identity has on maintaining professional standards and the perceptions of responsibility in reporting.

We now turn to our final two hypotheses in Table 6, the variables for both 'uncertainty' and 'risk integrity' are positive and significant across the models in which they are included. The results of Model $3(F(6.55)=13.576$, $p<0.001)$ allow us to accept both $\mathrm{H} 4$ and H5. Regarding $\mathrm{H} 4$, we find higher levels of certainty are positively related to intention to report risk events. This provides further evidence that training increases certainty, enhances an individual's attitude towards reporting an event and generates confidence in the knowledge that (a) the process of reporting will itself be straightforward and (b) the organisation will respond positively. Well-trained employees become more informed in making valid judgments; importantly, they may also be more likely to dismiss colleagues' opinions when they intuitively 'know' their intention to report an event is right. This adds more weight to the importance of training for situational factors within a high-error management climate, particularly given how significant an individual perceives an event to be, and their confidence of being able to see it through to a successful conclusion are related to reporting intention.

The supporting of $\mathrm{H} 5$ is also in line with the notion that control in seeing the reporting of a risk event through to an effective resolution may be key. We take this as further robust testing of PBC and additional evidence of a link between intention to report and protocols and procedures within the work environment. As per Martin and Cullen (2006), this demonstrates that employees who fully reflect on the reporting process and, based on this knowledge, can calculate the chances of success are more likely to escalate risk events. Although specific to the investment bank domain this result resonates with the 'Situation Awareness' and 'Decision Making' non-technical skills required by financial traders as outlined by Leaver and Reader (2016a, p. 714) in reporting risk events.

Our results also concur with Treviño et al. (2006) and Kohlberg (1969), who posit that individuals bring personal characteristics such as moral awareness and moral judgment into the workplace and that perceptions of the ethical work climate impact on behaviour in institutions where there is a tendency towards selfishness. However, this effect is not unidirectional, we also witness the effect that the error management climate has on the risk reporting intention of employees. In line with Brown et al. (2005), Van Dyck et al. (2005) and Leaver and Reader, (2016a), we find clear structures, processes and leadership to be influential. This also lends weight to the suggestion that leaders, through their own conduct, can shape the actions of individuals in high-error management climates; and to the argument that situational factors such as promotion and remuneration policies should remain consistent (Trevino 1986; Church et al. 2005), thus further encouraging compliant behaviour. What we do not discover is evidence of the formation of pressures to report due to the norms of reporting by peers that influence behaviour or a shared identity into which individuals attempt to fit (Reichers and Schneider 1990).

\section{Conclusion}

The dramatic events of recent years have starkly underlined the fashionable dictum that banks and other financial institutions are 'too big to fail'. Of course, the true message behind this maxim is that they cannot be allowed to fail; and yet the irony is that in reality they fail again and again. They fail on a very fundamental level whenever a risk event goes unreported or unchecked; and, as we have seen, it is the individual who is usually - if not always - presented with an opportunity to block the path towards potential catastrophe.

There is literally no telling what might happen if and when an individual chooses not to act in these circumstances. As stated at the outset, the consequences might take the form of small but significant losses or major and far-reaching scandals. In all likelihood, depending on seriousness, there will be some cost to the relevant 
institution, to the industry as a whole or to the wider economy and those who exist within it.

The above offers a sobering context in which to consider both the consequences of inaction and the implications of our findings. To put the matter bluntly: there is invariably a price to pay for failing to report a risk event, and the price is sometimes extraordinarily high. The Financial Conduct Authority Final Notices that provided the foundations for our study highlight how a lack of management and control, an absence of adequate risk management systems and poor training are frequently at the root of the decision not to escalate a risk event. With this in mind, the central goal of our research was to deliver a more comprehensive understanding of individual behaviour and the reporting of risk within a financial institution. Building on the work of Bryce et al. (2013), we used a mixed-methods approach, combining an innovative version of the classic dictator game with the Theory of Planned Behaviour (TPB), to test for levels of prosocial behaviour whilst examining intentions to report risk.

Our adapted dictator game produced a three-peaked distribution of results. Significantly, levels of purely selfish, purely altruistic and prosocial behaviour were all higher than the averages reported by Engel (2011) in his meta-study of dictator games. Most importantly, of the three, it was purely selfish behaviour that dominated.

Our subsequent application of TPB produced results broadly in line with Bryce et al. (2013). Two of the principal variables of TPB-Attitude (ATT) and Perceived Behavioural Control (PBC) - were found to significantly influence intention to report a risk event, whereas the third, Subjective Norm ( $\mathrm{SN}$ ), was found to be surprisingly insignificant (in contrast to Ellis and Arieli 1999). However, this may make sense: the purely selfish dominated our adapted dictator game, and those whose behaviour is purely selfish will tend to value their own ideas and opinions above those of others.

Such individuals have a clear notion of whether a risk event should be reported. For them it is vital that (a) they believe the event to be important (ATT) and (b) they feel confident in their ability to see the issue through to a successful conclusion (PBC). This being the case, it follows that management should be aware of such tendencies and should devise and implement risk reporting policies and practices, including training and education, that not only accommodate but make the most of them. If employees' decisions are not significantly influenced by the 'team', cultural norms or a shared climate of behaviour (SN), as per our findings, then effective coercion and compliance must be derived from elsewhere. It may well be beneficial for the organisation under investigation to consider enhancing team training around risk reporting and group learning from incidents in order to instil a stronger identity in relation to error reporting within the group.
It is tempting, of course, to be alarmed by the juxtaposition of the word 'selfish' and the term 'financial institution'. Cynics might well contend that the dominance of purely selfish behaviour is among the last things such an organisation needs. Not least amid the lingering effects of the global financial crisis and with new scandals consistently emerging to undermine the fight to regain public trust, the knee-jerk response may well be a negative one.

Yet this need not be the case. As we have shown, mapping the ethical behaviour of individuals within financial institutions may allow that very same behaviour to be exploited in a positive way. In essence, to promote the reporting of risk events it is first necessary to grasp the preconditions that make reporting more likely. By appreciating why employees think as they do, and recognising what drives their decisions, it should be possible to support the characteristics of a high-error management climate, thus strengthening the relationship between the employee and their error management climate.

\section{Limitations}

The results of this study are constrained by a number of factors, which at times provide evidence of a need for future research in the area of risk reporting within the financial services industry. Firstly, the use of a survey that implements the TPB was chosen due to the limited time offered to the research team within the employee's work environment. However, there may be a difference between the use of intention as a measure of an employee's perceived likelihood of reporting a risk event and actually reporting as outlined by Mesmer-Magnus and Viswesvaran (2006) and Taylor and Curtis (2010). This is further exacerbated by a lack of ability to directly query subjects as to the exact number of past experiences they have in the reporting of risk events and how these were treated by management, as the host organisation was reluctant to allow access of any kind should these questions be raised in survey form. It is well known within the error management literature (Van Dyck et al. 2005; Gronewold et al. 2013) that past experiences in the reporting of errors, and how these queries were treated, will affect the prevalence of future reporting. Unfortunately, in this current study this past experience baseline was not able to be captured; however, it must be noted that the intention to report was strong within the study with a mean response of 5.83 to the dependent variable. The collection of the aforementioned variables would have allowed for a more granular analysis of the intention to act in the future, thus allowing for more precise interventions to be determined.

Secondly, the importance of call centre employees to the organisation should not be understated; however, the lack of a professional body by which they can identify and 
group themselves may make the results less generalisable to professions in which there is a strong sense of professional identity, i.e. accountancy (Taylor and Curtis 2010). This may go some way to explain the lack of effect SN has on this group of subjects in the work environment. In addition, the call centre setting by its very nature makes the generalisation of results more difficult as they are renowned for high levels of 'employee churn' that makes the process of staff development and learning more difficult to embed (Malhotra and Mukherjee 2004; Schlesinger and Heskett (1991).

This may hamper an employee's ability to learn and understand the error management climate in which they are immersed as colleagues around them may move through the organisation regularly. This rapid turnover of staff will undoubtedly make the task of creating and developing a high-error management climate by the organisation under investigation more difficult. However, it should be noted that in this current study over half of staff were employed by the organisations for 3 years; nonetheless, this is not the case in all call centres. Thirdly, the ability of our 2-module methodology to capture actual prosocial behaviour whilst inferring error management behaviour and ultimately ethical climate via the TPB is not only innovative but provides a new methodological direction for future investigations of error management. Our choice of an adapted classic dictator game in order to capture elements of deception was not taken lightly, this experimental design is robust, but it is limited in its ability to link behaviour to inferences as captured by Module 2the survey. In order to minimise subject bias in their decision-making during the execution of the Module 1 experiment they must be guaranteed anonymity in their decision-making. The importance of subjects' making decisions anonymously was postulated in Smith (1976) and is standard experimental and ethical practice when conducting the experimental games with an element of cheating (Fischbacher and Föllmi-Heusi 2013). If we had been able to link the decision-making of both modules at the individual level our results could have probed the existence of an intrinsic link between prosocial behaviour and error management climate within the working environment of the employees.

\section{Future Research}

The results of this current study highlight the scope for future research in areas of error management climate as applied to risk reporting within the financial services industry. The recent influx of new regulations such as Solvency II to govern the internal management and ultimately measure the effectiveness of internal processes of operational risk within financial organisations will act as a catalyst to new studies. It should be noted that the financial services industry is rather late to the table of formalised internal risk reporting, with the healthcare and aviation industries considered best practice in this area. Although the consequences of catastrophic failures in these industries are in no way comparable to that of the financial services industry the 'see something, say something' mantra as posited by 'just culture' in these industries is pertinent to this current study and future research in financial services risk reporting. Future research that provides an ability to cross-compare not only the risk reporting systems of different industries but also different professions, types of errors, and reporting behaviour within those industries, will not only assist in identifying best practice but could lead to real-world implementations of effective interventions within the financial services industry. This concept of cross-industry pollination of risk processes is not without precedent, as the mandatory pre-flight cockpit checklist as implemented in the aviation industry has recently been successfully adapted by the World Health Organisation in an attempt to reduce surgical errors.

This current study along with others that have preceded it (Gronewold et al. 2013) suffers from an inability to conduct a longitudinal study, in which interventions (e.g. training, simulation) can be tested and retested for stability and depreciation in effectiveness over time. Future studies that have the ability to access a financial services organisation and test the saliency of their error management climate in situ over a prolonged period of time, whilst observing behaviour in an ontological manner, will benefit from capturing the development of norms (both seen and unseen) within the work environment. Further, the ability to compare the intention to report from those in the past has reported risk events and those who haven't would provide a better understanding as to the effects of past experience of the error management climate in future reporting. However, given the business sensitivity and confidentiality that shrouds the financial services industry, the embedded nature of such an ontological study or a between-group comparison may well be more difficult to implement in reality.

Funding This study was funded by a 'Seedcorn' Grant from the Institute of Chartered Accountants Scotland. This work was also supported by the Economic and Social Research Council [grant number ES/L000776/1], previous versions of this paper also received comments and suggestions from delegates of the ESRC 'Lessons in the Management of People Risk' Seminar Series and is considered an output of this research grant.

\section{Compliance with Ethical Standards}

Conflict of interest Cormac Bryce declares that he has no conflict of interest, Thorsten Chmura declares that he has no conflict of interest, Robert Webb declares that he has no conflict of interest, Carly 
Cheevers declares that she has no conflict of interest, Joel Stiebale declares that he has no conflict of interest.

Ethical Approval All procedures performed in studies involving human participants were in accordance with the ethical standards of the institutional and/or national research committee and with the 1964 Declaration of Helsinki and its later amendments or comparable ethical standards.

Informed Consent Informed consent was obtained from all individual participants included in the study.

Open Access This article is distributed under the terms of the Creative Commons Attribution 4.0 International License (http://crea tivecommons.org/licenses/by/4.0/), which permits unrestricted use, distribution, and reproduction in any medium, provided you give appropriate credit to the original author(s) and the source, provide a link to the Creative Commons license, and indicate if changes were made.

\section{Appendix 1: Photographs of Experimental Setting}

Each participant took an envelope out of this box randomly. There was a 90/10 split between envelopes containing eight $£ 1$ coins and envelopes containing four $£ 1$ coins and four chocolate coins (Fig. 3).

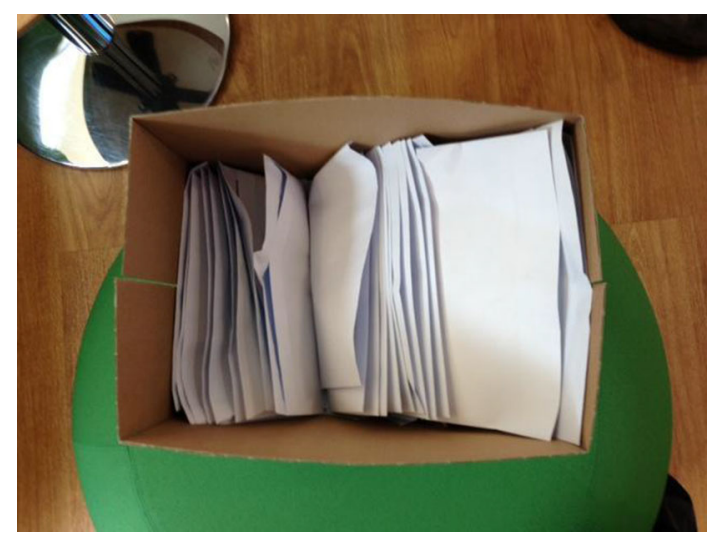

Fig. 3 Box with envelopes

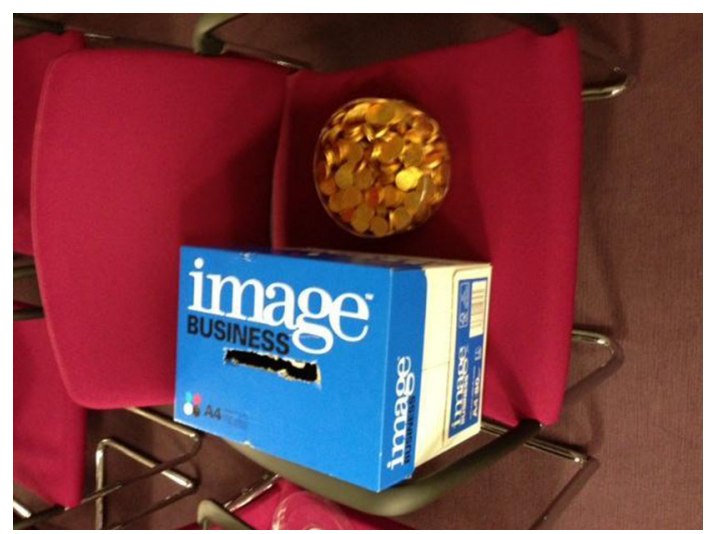

Fig. 4 Second box and chocolate coins
Each participant opened their chosen envelope, took out the money and was then able to put chocolate coins in before the envelope was resealed and placed in a second box (Fig. 4).

\section{Appendix 2: Subject Instruction Leaflet}

Welcome to the experiment. In this experiment, you will be able to earn money and send money to another call centre.

In the envelope experiment you will play with another participant. You are in the role of the sender. You will pick an envelope that either has $£ 8$ coins, or $£ 4$ coins and 4 chocolate coins. Nobody will be able to see whether you received an envelope with $£ 8$ or $£ 4$. You will go to a room and take whatever you like out of the envelope. Nobody will be able to see what you take out and what will be left in the envelope. You will take the money in a room where nobody can observe what you do. You are the only person from the subject pool who knows what envelope you took. Neither the experimenter nor other participants are able to track your decisions back to you individually.

We will put a box with chocolate coins next to the box where you put the envelope in, after you have made your decision of how much money you will send.

Now you will reseal and place the envelope into the box situated beside the chocolate coins, and this will be sent to the receiver who is a colleague in a sister call centre within your organisation.

Your pay-off will be what you took out of the envelope and the receiver's pay-off will be what you left in the envelope.

There is a probability of $2 \%$ that the true value of the envelope at the time you received it will be revealed. Please see the probabilities in the figure below.

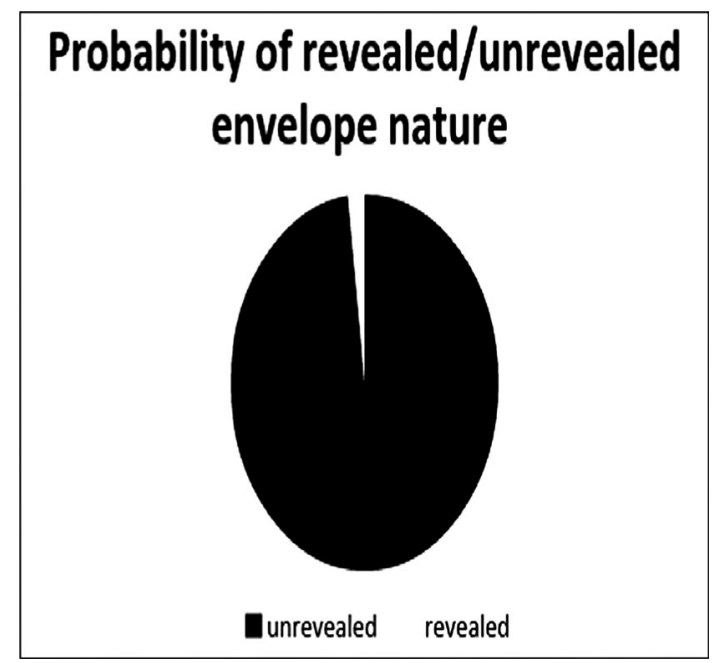




\section{Appendix 3: TPB Survey Construct Questions}

\section{Intention}

To what extent do you agree with each of the following statements?

\begin{tabular}{lllllll}
$\begin{array}{l}\text { Strongly } \\
\text { agree }\end{array}$ & Agree & $\begin{array}{l}\text { Agree to } \\
\text { some extent }\end{array}$ & $\begin{array}{l}\text { Neither/ } \\
\text { Nor }\end{array}$ & $\begin{array}{l}\text { Disagree to } \\
\text { some extent }\end{array}$ & Disagree & $\begin{array}{l}\text { Strongly } \\
\text { disagree }\end{array}$ \\
\hline$\square$ & $\square$ & $\square$ & $\square$ & $\square$ & $\square$ & $\square$ \\
$\square$ & $\square$ & $\square$ & $\square$ & $\square$ & $\square$ & $\square$ \\
$\square$ & $\square$ & $\square$ & $\square$ & $\square$ & $\square$ & $\square$
\end{tabular}

\section{Attitude}

Overall, I think that reporting operational risk losses/events is...?

\begin{tabular}{lllllll}
\hline Very effective & Effective & Somewhat effective & Neither/Nor & Somewhat ineffective & Ineffective & Very ineffective \\
\hline$\square$ & $\square$ & $\square$ & $\square$ & $\square$ & Harmful & Very harmful \\
\hline Very beneficial & Beneficial & Somewhat beneficial & Neither/Nor & Somewhat harmful & $\square$ & $\square$ \\
\hline$\square$ & $\square$ & $\square$ & $\square$ & $\square$ & Foolish & Very foolish \\
\hline Very wise & Wise & Somewhat wise & Neither/Nor & Somewhat foolish & $\square$ & $\square$ \\
\hline$\square$ & $\square$ & $\square$ & $\square$ & $\square$ & $\square$
\end{tabular}

\section{Subjective Norm}

To what extent do you agree with each of the following statements?

\begin{tabular}{|c|c|c|c|c|c|c|c|}
\hline & $\begin{array}{l}\text { Strongly } \\
\text { agree }\end{array}$ & Agree & $\begin{array}{l}\text { Agree to } \\
\text { some extent }\end{array}$ & $\begin{array}{l}\text { Neither/ } \\
\text { Nor }\end{array}$ & $\begin{array}{l}\text { Disagree to } \\
\text { some extent }\end{array}$ & Disagree & $\begin{array}{l}\text { Strongly } \\
\text { disagree }\end{array}$ \\
\hline $\begin{array}{l}\text { Most people I know would report operational risk losses/ } \\
\text { events }\end{array}$ & $\square$ & $\square$ & $\square$ & $\square$ & $\square$ & $\square$ & $\square$ \\
\hline $\begin{array}{l}\text { People that are important to me would think that I should } \\
\text { report operational risk losses/events }\end{array}$ & $\square$ & $\square$ & $\square$ & $\square$ & $\square$ & $\square$ & $\square$ \\
\hline $\begin{array}{l}\text { People that are important to me would approve of me } \\
\text { reporting operational risk losses/events }\end{array}$ & $\square$ & $\square$ & $\square$ & $\square$ & $\square$ & $\square$ & $\square$ \\
\hline $\begin{array}{l}\text { My colleagues think it is appropriate for me to report } \\
\text { operational risk losses/events }\end{array}$ & $\square$ & $\square$ & $\square$ & $\square$ & $\square$ & $\square$ & $\square$ \\
\hline
\end{tabular}




\section{Perceived Behavioural Control}

To what extent do you agree with each of the following statements?

\begin{tabular}{|c|c|c|c|c|c|c|c|c|c|}
\hline & \multicolumn{2}{|c|}{$\begin{array}{l}\text { Strongly } \\
\text { agree }\end{array}$} & Agree & \multicolumn{2}{|c|}{$\begin{array}{l}\text { Agree to some } \\
\text { extent }\end{array}$} & $\begin{array}{l}\text { Neither/ } \\
\text { Nor }\end{array}$ & $\begin{array}{l}\text { Disagree to } \\
\text { some extent }\end{array}$ & Disagree & $\begin{array}{l}\text { Strongly } \\
\text { disagree }\end{array}$ \\
\hline $\begin{array}{l}\text { If I wanted to I could easily report operational } \\
\text { risk losses/events }\end{array}$ & $\square$ & & $\square$ & $\square$ & & $\square$ & $\square$ & $\square$ & $\square$ \\
\hline $\begin{array}{l}\text { For me to report operational risk losses/events is } \\
\text { easy }\end{array}$ & $\square$ & & $\square$ & $\square$ & & $\square$ & $\square$ & $\square$ & $\square$ \\
\hline $\begin{array}{l}\text { I have control over my choice to report } \\
\text { operational risk losses/events }\end{array}$ & $\square$ & & $\square$ & $\square$ & & $\square$ & $\square$ & $\square$ & $\square$ \\
\hline \multicolumn{10}{|l|}{ To what extent would you say...? } \\
\hline & & $\begin{array}{l}\text { Very } \\
\text { likely }\end{array}$ & & ikely & $\begin{array}{l}\text { Somewhat } \\
\text { likely }\end{array}$ & $\begin{array}{l}\text { Neithe } \\
\text { Nor }\end{array}$ & $\begin{array}{l}\text { Somewhat } \\
\text { unlikely }\end{array}$ & Unlikely & $\begin{array}{l}\text { Very } \\
\text { unlikely }\end{array}$ \\
\hline $\begin{array}{l}\text { I would be able to report operational risk losses/ev } \\
\text { should they arise }\end{array}$ & vents & $\square$ & $\square$ & & $\square$ & $\square$ & $\square$ & $\square$ & $\square$ \\
\hline
\end{tabular}

\section{Uncertainty}

To what extent do you agree with each of the following statements?

\begin{tabular}{|c|c|c|c|c|c|c|c|}
\hline & $\begin{array}{l}\text { Strongly } \\
\text { agree }\end{array}$ & Agree & $\begin{array}{l}\text { Agree to } \\
\text { some extent }\end{array}$ & $\begin{array}{l}\text { Neither/ } \\
\text { Nor }\end{array}$ & $\begin{array}{l}\text { Disagree to } \\
\text { some extent }\end{array}$ & Disagree & $\begin{array}{l}\text { Strongly } \\
\text { disagree }\end{array}$ \\
\hline $\begin{array}{l}\text { I am sure of my knowledge and understanding of what } \\
\text { operational risk losses/events are }\end{array}$ & $\square$ & $\square$ & $\square$ & $\square$ & $\square$ & $\square$ & $\square$ \\
\hline $\begin{array}{l}\text { I am aware of the correct reporting channels for the } \\
\text { reporting of operational risks losses/events }\end{array}$ & $\square$ & $\square$ & $\square$ & $\square$ & $\square$ & $\square$ & $\square$ \\
\hline
\end{tabular}

When you come across various risk losses/events how sure are you of what to choose to report as an operational risk loss/event? (Tick one only)

\begin{tabular}{lllllll}
\hline Very sure & Sure & Somewhat sure & Neither/Nor & Somewhat unsure & Unsure & Very unsure \\
\hline$\square$ & $\square$ & $\square$ & $\square$ & $\square$ & $\square$ & $\square$ \\
\hline
\end{tabular}

\section{Risk Integrity}

To what extent do you agree with each of the following statements?

\begin{tabular}{llllll}
\hline & $\begin{array}{l}\text { Strongly } \\
\text { agree }\end{array}$ & Agree & $\begin{array}{l}\text { Agree to } \\
\text { some extent }\end{array}$ & $\begin{array}{l}\text { Neither/ } \begin{array}{l}\text { Disagree to } \\
\text { some extent }\end{array} \\
\text { soragree }\end{array} \quad \begin{array}{l}\text { Strongly } \\
\text { disagree }\end{array}$ \\
\hline $\begin{array}{l}\text { I would be prepared to invest a lot of effort in } \\
\text { operational risk reporting }\end{array}$ & $\square$ & $\square$ & $\square$ & $\square$ & $\square$ \\
$\begin{array}{l}\text { I would like more information in order to understand my } \\
\text { institution's operational risk policy }\end{array}$ & $\square$ & $\square$ & $\square$ & $\square$ & $\square$ \\
$\begin{array}{l}\text { Having a good risk management track record is } \\
\text { important to me }\end{array}$ & $\square$ & $\square$ & $\square$ & $\square$ & $\square$ \\
\hline
\end{tabular}




\section{References}

Ajzen, I. (1988). Attitudes, personality and behaviour. Chicago: Illinois Press.

Ajzen, I. (1991). The Theory of Planned Behaviour. Organizational Behaviour and Human Decision Processes, 50, 179-211.

Arnaud, A., \& Schminke, M. (2012). The ethical climate and context of organizations: A comprehensive model. Organization Science, 23(6), 1767-1780.

Ashton, J. (2014). The scale and scope of financial mis-selling. In T. Harrison \& H. Estelami (Eds.), Chapter 30: The Routledge companion to financial services management. London: Routledge.

Bandura, A. (1986). Social foundations of thought and action: A social cognitive theory. Englewood Cliffs, NJ: Prentice-Hall.

Bardsley, N. (2008). Dictator game giving. Altruism or artefact? Experimental Economics, 11(2), 122-133.

Basel Committee on Banking Supervision. (2006). Core principles for effective banking supervision-Final document. Basel: Bank for International Settlements.

Ben-Ner, A., Putterman, L., Kong, F., \& Magan, D. (2004). Reciprocity in a two-part dictator game. Journal of Economic Behavior \& Organization, 53, 333-352.

Binmore, K. (1994). Playing fair: Game theory and the social contract (Vol. I). Cambridge, MA: MIT Press.

Binmore, K. (1998). Just playing: Game theory and the social contract (Vol. 2). Cambridge, MA: MIT Press

Binmore, K. (1999). Why experiment in economics? Economic Journal, 109(2), F16-F24.

Binmore, K., \& Shaked, A. (2010). Experimental economics: Where next? Journal of Economic Behavior and Organization, 73, $87-100$

Biron, M. (2010). Negative reciprocity and the association between perceived organizational ethical values and organizational deviance. Human Relations, 63(6), 875-897.

Brief, A. P., \& Motowidlo, S. J. (1986). Prosocial organizational behaviors. The Academy of Management Review, 11(4), 710-720.

Brown, M., Treviño, L. K., \& Harrison, D. (2005). Ethical leadership: A social learning perspective for construct development and testing. Organizational Behavior and Human Decision Processes, 97, 117-134.

Bryce, C., Cheevers, C., \& Webb, R. (2013). Operational risk escalation and the theory of planned behaviour: An empirical analysis of UK call centres. International Review of Financial Analysis, 30, 298-307.

Bryce, C., Webb, R., \& Adams, J. (2011). Internal loss data collection implementation: Evidence from a major UK financial institution. Journal of Risk Research, 14(10), 1161-1176.

Bryce, C., Webb, R., Cheevers, C., Clark, G., \& Ring, P. (2016). Should the insurance sector be banking on risk escalation for solvency II? International Review of Financial Analysis, 34, 131-139.

Burks, V., \& Krupka, E. L. (2012). A multimethod approach to identifying norms and normative expectations within a corporate hierarchy: Evidence from the financial services industry. Management Science, 58(1), 203-217.

Cassematis, P. G., \& Wortley, R. (2013). Prediction of whistleblowing or non-reporting observation: The role of personal and situational factors. Journal of Business Ethics, 117(3), 615-634.

Catino, M., \& Patriotta, G. (2013). Learning from errors: Cognition, emotions and just culture at the Italian Air Force. Organization Studies, 34(4), 437-467.

Chan, S. C., \& Lu, M. T. (2004). Understanding internet banking adoption and use behavior: A Hong Kong perspective. Journal of Global Information Management, 12(3), 21-43.
Chmura, T., Engel, C., Englerth, M., \& Pitz, T. (2010). At the mercy of the prisoner next door-using an experimental measure of selfishness as a criminological tool, No 2010/27. Bonn: Max Planck Institute for Research on Collective Goods.

Chmura, T., Goerg, S., \& Weiss, P. (2016). Natural groups and economic characteristics as driving forces of wage discrimination. European Economic Review, 90, 178-200.

Church, B., Gaa, J. C., Nainar, S. M. K., \& Shehata, M. M. (2005). Experimental evidence relating to the person-situation interactionist model of ethical decision making. Business Ethics Quarterly, 15(3), 363-383.

Cronbach, L. J. (1970). Essentials of psychological testing (3rd ed.). New York: Harper \& Row.

Dana, J., Cain, D. M., \& Dawes, R. M. (2006). What you don't know won't hurt me: Costly (but Quiet) exit in dictator games. Organizational Behavior and Human Decision Processes, 100, 193-201.

De Cremer, D., \& van Lange, P. A. M. (2001). Why prosocials exhibit greater cooperation than proselfs: The roles of social responsibility and reciprocity. European Journal of Personality, 15, 5-18.

Dennison, C. M., \& Shepherd, R. (1995). Adolescent food choice: An application of the theory of planned behaviour. Journal of Human Nutrition \& Dietetics, 8(4), 9-23.

Dohmen, Y., Falk, A., Huffman, D., Sunde, U., Schupp, J., \& Wagner, G. (2011). Individual risk attitudes: Measurement, determinants, and behavioral consequences. Journal of The European Economic Association, 9(3), 522-550.

Dozier, J. B., \& Miceli, M. P. (1985). Potential predictors of whistleblowing: A prosocial behavior perspective. Academy of Management Review, 10(4), 823-836.

Eckel, C., \& Grossmann, P. (1996). Altruism in anonymous dictator games. Games and Economic Behavior, 16, 181-191.

Eden, D., \& Aviram, A. (1993). Self-efficacy training to speed reemployment: Helping people to help themselves. Journal of Applied Psychology, 78(3), 352-360.

Ellis, S., \& Arieli, S. (1999). Predicting intentions to report administrative and disciplinary infractions: Applying the reasoned action model. Human Relations, 52(7), 947-967.

Engel, C. (2011). Dictator games: A meta study. Experimental Economics, 14(4), 583-610.

Falk, A., Fehr, E., \& Fischbacher, U. (2003). On the nature of fair behavior. Economic Inquiry, 41(1), 20-26.

Fehr, E., Fischbacher, U., Rosenbladt, B., Schupp, J., \& Wagner, G. (2003). A nationwide laboratory-Examining trust and trustworthiness by integrating behavioural experiments into representative surveys. Working paper no. 141, Institute for Empirical Research in Economics, University of Zurich.

Fischbacher, U., \& Föllmi-Heusi, F. (2013). Lies in disguise-An experimental study on cheating. Journal of the European Economic Association, 11, 525-547.

Forsythe, R., Horowitz, R., Savin, N., \& Sefton, M. (1994). Fairness in simple bargaining experiments. Games and Economic Behavior, 6, 347-369.

Goette, L., Huffman, D., \& Meier, S. (2006). The impact of group membership on cooperation and norm enforcement: Evidence using random assignment to real social groups. American Economic Review, 96(2), 212-216.

Grant, A. M., \& Berg, J. M. (2011). Prosocial motivation at work: When, why, and how making a difference makes a difference. In K. Cameron \& G. Spreitzer (Eds.), Oxford handbook of positive organizational scholarship (pp. 28-44). New York: Oxford University Press.

Gronewold, U., Gold, A., \& Salterio, S. (2013). Reporting self-made errors: The impact of organizational error-management climate and error type. Journal of Business Ethics, 117, 189-208. 
Guth, W., Huck, S., \& Ockenfels, P. (1996). Two-level ultimatum bargaining with incomplete information. An Experimental Study, Economic Journal, 106(436), 593-604.

Haidt, J. (2000). The positive emotion of elevation. Prevention and Treatment, 3(3) posted March 7, 2000.

Haidt, J. (2003). Elevation and the positive psychology of morality. In C. L. M. Keyes \& J. Haidt (Eds.), Flourishing: Positive psychology and the life well-lived (pp. 275-289). Washington, DC: American Psychological Association.

Hain, S. (2009). Managing operational risk: Creating incentives for reporting and disclosing. Journal of Risk Management in Financial Institutions, 2(3), 284-300.

Hodgson, G. (2012). On the limits of rational choice theory. Economic Thought, 1(1) (Published online).

Hoffman, E., McCabe, K., Shachat, K., \& Smith, V. (1994). Preferences, property rights, and anonymity in bargaining games. Games and Economic Behavior, 7, 346-380.

Hsu, M. H., \& Chiu, C. M. (2004). Internet self-efficacy and electronic service acceptance. Decision Support Systems, 38(3), 369-381.

IRM. (2012). Risk culture: Guidance from the Institute of Risk Management. London: Institute of Risk Management.

Kahneman, D., Knetsch, Jack L., \& Thaler, R. H. (1986). Fairness and the assumptions of economics. Journal of Business, 59, S285-S300.

Kaplan, S. E., \& Schultz, J. J. (2007). Intentions to report questionable acts: An examination of the influence of anonymous reporting channel, internal audit quality, and setting. Journal of Business Ethics, 71(2), 109-124.

Kaplan, S. E., \& Whitecotton, S. M. (2001). An examination of auditors' reporting intentions when another auditor is offered client employment. Auditing: A Journal of Practice \& Theory, 20, 45-64.

Kenny, K. (2014). Banking compliance and dependence corruption: Towards an attachment perspective. Law and Financial Markets Review, 8(2), 165-177.

Khadjavi, M., \& Lange, A. (2013). Prisoners and their dilemma. Journal of Economic behaviour and Organisation, 92, 163-175.

Kish-Gephart, J. J., Harrison, D. A., \& Trevino, L. K. (2010). Bad apples, bad cases, and bad barrels: Meta-analytic evidence about sources of unethical decisions at work. Journal of Applied Psychology, 95, 1-31.

Kohlberg, L. (1969). Stage and sequence: The cognitive development approach to socialization. In D. A. Goslin (Ed.), Handbook of socialization theory and research (pp. 347-480). Chicago: Rand McNally.

KPMG Forensic. (2009). Never again: Risk management in banking beyond the credit crisis. KPMG LLP, a Delaware Limited Liability Partnership.

KPMG Forensic. (2013). Integrity survey. KPMG LLP, a Delaware Limited Liability Partnership.

Kuenzi, M., \& Schminke, M. (2009). Assembling fragments into a lens: A review, critique, and proposed research agenda for the organizational work climate literature. Journal of Management, 35(3), 634-717.

Landis, S. K., Sherman, M. F., Piedmont, R. L., Kirkhart, M. W., Rapp, E. M., \& Bike, D. H. (2009). the relation between elevation and self-reported prosocial behavior: Incremental validity over the five-factor model of personality. The Journal of Positive Psychology., 4(1), 71-84.

Leaver, M., \& Reader, T. (2016a). Human factors in financial trading: An analysis of trading incidents. Journal of the Human Factors and Ergonomics Society, 58(6), 814-832.

Leaver, M., \& Reader, T. (2016b). Non-technical skills for managing risk and performance in financial trading. Journal of Risk Research, 19(6), 687-721.
Leeds, R. (1963). Altruism and the norm of giving. Merrill Palmer Quarterly of Behavior and Development, 9(3), 229-240.

Lin, H. F. (2010). Applicability of the extended theory of planned behaviour in predicting job seeker intentions to use job-search websites. International Journal of Selection and Assessment, 18(1), 64-74.

Ma, Q., \& Liu, L. (2005). The role of internet self-efficacy in the acceptance of web-based electronic medical records. Journal of Organizational and End User Computing, 17(1), 38-57.

Malhotra, N., \& Mukherjee, A. (2004). The relative influence of organisational commitment and job satisfaction on service quality of customer-contact employees in banking call centres. Journal of Services Marketing, 18(3), 162-174.

Martin, K. D., \& Cullen, J. B. (2006). Continuities and extensions of ethical climate theory: A meta-analytic review. Journal of Business Ethics, 69(2), 175-194.

Mayer, D. M., Nurmohamed, S., Treviño, L., Shapiro, D. L., \& Schminke, M. (2013). Encouraging employees to report unethical conduct internally: It takes a village. Organizational Behavior and Human Decision Processes, 121, 89-103.

McCabe, D. (2009). Enterprise contested: Betwixt and between the discourses of career and enterprise in a UK bank. Human Relations, 62(10), 1551-1579.

Meglino, B. M., \& Korsgaard, M. A. (2004). Considering rational self-interest as a disposition: Organizational implications of other orientation. Journal of Applied Psychology, 89, 946-959.

Meglino, B., \& Korsgaard, M. (2006). Considering situational and dispositional approaches to rational self-interest: An extension and response to De Dreu. Journal of Applied Psychology, 92(6), 1253-1259.

Mesmer-Magnus, J. R., \& Viswesvaran, C. J. (2006). Whistleblowing in organizations: An examination of correlates of whistleblowing intentions, actions, and retaliation. Journal of Business Ethics, 62(3), 227-297.

Miceli, M. P., Near, J. P., Rehg, M. T., \& Van Scotter, J. R. (2012). Predicting employee reactions to perceived organizational wrongdoing: Demoralization, justice, proactive personality, and whistle-blowing. Human Relations, 65(8), 923-954.

Mikes, A., \& Kaplan, R. S. (2013). Managing risks: Towards a contingency theory of enterprise risk management. Harvard Business School Working Paper 13-063.

Miller, D. L., \& Thomas, S. (2005). The impact of relative position and relational closeness on the reporting of unethical acts. Journal of Business Ethics, 61(4), 315-328.

Moosa, I. A. (2007). Operational risk: A survey. Financial Markets, Institutions and Instruments, 16(4), 167-200.

Morrison, E. W. (2011). Employee voice behavior: Integration and directions for future research. Academy of Management Annals, 5(1), 373-412.

Naef, M., \& Schupp, J. (2009). Measuring trust: Experiments and surveys in contrast and combination. SOEP papers on Multidisciplinary Panel Data Research, Vol. 167, DIW Berlin, The German Socio-Economic Panel (SOEP).

Nunnally, J. C., \& Bernstein, I. H. (1994). Psychometric theory (3rd ed.). New York: McGraw-Hill.

Palermo, T., Power, M., \& Ashby, S. (2016). Navigating institutional complexity: The production of risk culture in the financial sector. Journal of Management Studies. doi:10.1111/joms.12241.

Pavlou, P. A., \& Fygenson, M. (2006). Understanding and predicting electronic commerce adoption: An extension of the theory of planned behaviour. MIS Quarterly, 301(1), $115-143$.

Peterson, D. K. (2002). Deviant workplace behavior and the organization's ethical climate. Journal of Business and Psychology, 17(1), 47-53. 
Pinder, C. C., \& Harlos, K. P. (2001). Employee silence: Quiescence and acquiescence as responses to perceived injustice. Research in Personnel and Human Resources Management, 20, 331-369.

Power, M. (2005). The invention of operational risk. Review of International Political Economy, 12(4), 577-599.

Power, M. (2007). Organized uncertainty: Designing a world of risk management. Oxford: Oxford University Press.

Power, M., Ashby, S., \& Palermo, T. (2013). Risk culture in financial organisations: Final report. London: Financial Services Knowledge Transfer Network.

Reason, J. T. (2000). Human error: Models and management. British Medical Journal, 320(7237), 768-770.

Reichers, A. E., \& Schneider, B. (1990). Climate and culture: An evolution of constructs. In B. Schneider (Ed.), Organizational climate and culture (pp. 5-39). San Francisco: Jossey-Bass.

Resick, C. J., Hargis, M. B., Shao, P., \& Dust, S. B. (2013). Ethical leadership, moral equity judgments, and discretionary workplace behavior. Human Relations, 66(7), 951-972.

Ring, P., Bryce, C., \& Webb, R. (2014). Taking notice of risk culture-The regulator's approach. Journal of Risk Research. doi:10.1080/13669877.2014.983944.

Roberts, K. H., \& Bea, R. (2001). Must accidents happen? Lessons from high-reliability organisations. Academy of Management Executive, 15(3), 70-79.

Romani, S., \& Grappi, S. (2013). How companies' good deeds encourage consumers to adapt prosocial behavior. European Journal of Marketing, 48(5/6), 943-963.

Rybowiak, V., Garst, H., Frese, M., \& Batinic, B. (1999). Error Orientation Questionnaire (EOQ): Reliability, validity, and different language equivalence. Journal of Organizational Behavior, 20, 527-547.

Saks, A. M., \& Ashforth, B. E. (2000). Change in job search behaviors and employment outcomes. Journal of Vocational Behavior, 56(2), 277-287.

Schlesinger, L., \& Heskett, J. (1991). Breaking the cycle of failure in services. Sloan Management Review, 32, 17-28.

Schneider, B. (1975). Organizational climates: An essay. Personnel Psychology, 28(4), 447-479.

Simon, H. A. (1993). Altruism and economics. The American Economic Review. In Papers and proceedings of the 105th annual meeting of the american economic Association, 83(2), $156-161$

Smith, V. L. (1976). Experimental economics: Induced value theory. American Economic Review, 66, 274-279.
Taylor, E., \& Curtis, M. (2010). An examination of the layers of workplace influences in ethical judgments: Whistleblowing likelihood and perseverance in public accounting. Journal of Business Ethics, 93, 21-37.

Thaler, R. H. (1987). The psychology of choice and the assumptions of economics. In Alvin Roth (Ed.), Laboratory experiments in economics: Six points of view. Cambridge: Cambridge University Press.

Trevino, L. K. (1986). Ethical decision making in organizations: A person-situation interactionist model. Academy of Management Review, 11, 601-617.

Treviño, L. K., Weaver, G. R., \& Reynolds, S. J. (2006). Behavioral ethics in organizations: A review. Journal of Management, 32(6), 951-990.

Uribe, C., Schweikhart, S., Pathak, D., Dow, M., \& Marsh, G. (2002). Perceived barriers to medical-error reporting: An exploratory investigation. Journal of Healthcare Management, 47, 263-279.

Van Dyck, C. (2009). The tragic 1996 Everest expedition: A tale of error culture. Netherlands Journal of Psychology, 65(1), 22-34.

Van Dyck, C., Frese, M., Baer, M., \& Sonnentag, S. (2005). Organizational error management culture and its impact on performance: A two-study replication. Journal of Applied Psychology, 90(6), 1228-1240.

Van Dyne, L., Ang, S., \& Botero, I. C. (2003). Conceptualizing employee silence and employee voice as multidimensional constructs. Journal of Management Studies, 40(6), 1359-1392.

Van Scotter, J. R., Miceli, M. P., Near, J. P., \& Rehg, M. T. (2005). 'What difference can one person make? Organizational dependence relations as predictors of whistle-blowing effectiveness. International Journal of Knowledge, Culture and Change Management, 4(1), 1356-1466.

Venkatesh, V., \& Brown, S. A. (2001). A longitudinal investigation of personal computers in homes. MIS Quarterly, 25(1), 71-102.

Victor, B., \& Cullen, J. (1987). A theory and measure of ethical climate in organizations. In W. C. Fredrick \& L. Preston (Eds.), Research in corporate social performance and policy (pp. 51-71). London: JAI.

Wang, Yau-De, \& Hsieh, Hui-Hsien. (2013). Organisational ethical climate, perceived organizational support, and employee silence: A cross-level investigation. Human Relations, 66(6), 783-802.

Zhao, B., \& Olivera, F. (2006). Error reporting in organizations. The Academy of Management Review, 31(4), 1012-1030. 